\title{
Modification of Double Oxide Film Defects with the Addition of Mo to An Al-Si-Mg Alloy
}

\author{
QI CHEN and W.D. GRIFFITHS
}

In this work, Mo was added into $\mathrm{Al}$ melt to reduce the detrimental effect of double-oxide film defect. An air bubble was trapped in a liquid metal (2L99), served as an analogy for double-oxide film defect in aluminum alloy castings. It was found that the addition of Mo significantly accelerated the consumption of the entrapped bubble by 60 pct after holding for 1 hour. 2 sets of testbar molds were then cast, with 2L99 and 2L99+ Mo alloy, with a badly designed running system, intended to deliberately introduce double oxide film defects into the liquid metal. Tensile testing showed that, with the addition of Mo, the Weibull modulus of the Ultimate Tensile Strength and pct Elongation was increased by a factor of 2.5 (from 9 to 23) and 2 (from 2.5 to 4.5), respectively. The fracture surface of 2L99+ Mo alloy testbars revealed areas of nitrides contained within bi-film defects. Cross-sections through those defects by Focused Ion Beam milling suggested that the surface layer were permeable, which could be as thick as $30 \mu \mathrm{m}$, compared to around $500 \mathrm{~nm}$ for the typical oxide film thickness. Transmission Electron Microscopy analysis suggested that the nitride-containing layer consisted of nitride particles as well as spinel phase of various form. The hypothesis was raised that the permeability of the nitride layers promote the reaction between the entrapped atmosphere in the defect and the surrounding liquid metal, reducing the defect size and decreasing their impact on mechanical properties.

https://doi.org/10.1007/s11663-020-02038-w

(C) The Author(s) 2021

\section{INTRODUCTION}

DOUBLE oxide film defects are thought to be one of the main defects in aluminum castings, responsible for both reduction and variation in mechanical properties. This concept was initially raised by Campbell ${ }^{[1]}$ who suggested that the oxidized surface film of a liquid $\mathrm{Al}$ alloy could be folded-over, dry-side to dry-side, due to surface turbulence of the liquid metal during the casting operation. After solidification, these doubled over oxide film defects would form a gas-filled crevice, captured in the casting and, consequently, create an initiation site for crack growth leading to the premature failure of the casting in service.

Campbell ${ }^{[1]}$ suggested that, when the ingate velocity exceeded $0.5 \mathrm{~ms}^{-1}$ the liquid metal would spurt into the mold cavity, creating a double oxide film defect. If the liquid metal velocity was less than $0.5 \mathrm{~ms}^{-1}$ the liquid metal would well up into the mold cavity and double

QI CHEN, W.D. GRIFFITHS are with the School of Metallurgy and Materials, College of Engineering and Physical Sciences, University of Birmingham, Birmingham, B15 2TT, UK. Contact email: Q.Chen9927@gmail.com

Manuscript submitted on June 23, 2020; accepted November 12, 2020.

Article published online January 5, 2021. oxide film defects could be avoided. Runyoro ${ }^{[2]}$ and $\mathrm{Lai}^{[3]}$ confirmed this hypothesis by use of a high speed camera and modelling. There have since been many trials to reduce the effect of the defect on the mechanical properties of castings by reducing the surface turbulence of the liquid metal during casting, either by design of the running system, ${ }^{[4,5]}$ or the use of a filter to remove prior inclusions to improve the cleanliness of the melt, ${ }^{[6]}$ but also to reduce the velocity of the liquid metal entering the mold. ${ }^{[7]}$

Despite the ability of these methods in some cases in limiting the effect of bifilm defects in some cases (i.e., double oxide film defects), in castings, there are still many cases where the introduction of large amounts of bifilm defects into castings is unavoidable, such as metal remelting and recycling processes, or the metal melt transferring process. Therefore, it remains necessary to understand the structure and behavior of this defect, for better understanding and control, and to find out ways to deactivate these defects in situ.

Nyahumwa ${ }^{[8]}$ proposed that the entrapped atmosphere in a double oxide film defect, (presumed to be largely air), might be consumed gradually by reaction with the surrounding melt, with initially oxygen and then nitrogen being consumed. When the majority of the entrapped atmosphere was depleted, the un-wetted sides of the double oxide film defects might reduce in size. 
However, the mechanism is unclear, e.g., the liquid metal might react with the entrapped atmosphere through rupture points of the oxide layers formed by the transformation of the oxide layer from amorphous alumina, to a crystalline $\gamma$-alumina state, before becoming $\alpha$-alumina. ${ }^{[9,10]}$ These transformations might introduce stresses to the oxide layer, e.g., the $\gamma$ - to $\alpha$-alumina transformation, which was associated with a 24 pct volume change, ${ }^{[11]}$ might cause the localized rupture of

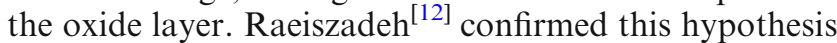
by trapping a bubble of air inside an aluminum melt, and observed that, initially, a reaction occurred between oxygen and the aluminum melt, forming alumina, which was followed by a reaction between $\mathrm{N}_{2}$ and $\mathrm{Al}$ to form AlN. El-Sayed ${ }^{[13]}$, using a Pore Gas Analyzer, reached a similar conclusion, that the majority of the oxygen in an air bubble was initially consumed before the reaction between $\mathrm{Al}$ and $\mathrm{N}$ took place. Aryafar et al. ${ }^{[14]}$ suggested that bonding of the two unwetted sides of the oxide layer may be possible, when the entrapped atmosphere in a bi-film defect was largely consumed.

However, the rupture of the oxide film might also enable hydrogen in the liquid metal to diffuse into the entrapped atmosphere of a bifilm defect, leading to its expansion. Gerrard and Griffiths ${ }^{[15]}$ suggested that the diffusion of hydrogen between the aluminum melt and into the internal atmosphere of a bifilm was five times greater through a porous layer of AIN compared to a continuous layer of alumina $\mathrm{Al}_{2} \mathrm{O}_{3}$. The effect of a bifilm defect on mechanical properties may, therefore, be determined by the combination of the expansion of bifilm defects caused by hydrogen diffusion and the reduction of the size of bifilm defects caused by the consumption of its entrapped atmosphere.

Due to the variation in size and orientation of the defects, their effects on mechanical properties have been unpredictable. Campbell and Green ${ }^{[16]}$ suggested that the distribution of the tensile properties in a defect-containing casting might follow a Weibull distribution, with a cut-off point at the upper end of the mechanical property data, which might be due to the limit of the properties of the material itself, and a long tail caused by the effect of defects of varying size, location and orientation.

Previous research by the authors investigated the effect of a range of transition metals additions on an Al-Si-Mg alloy (2L99), suggested that the addition of about 0.4 wt pet Mo or $\mathrm{W}^{[17,18]}$ could double the Weibull moduli of the UTS. This work was aimed at further investigating, through a bubble trapping experiment, followed by the tensile tests and the examination of the structures of bifilm defects found in the casting in situ (through SEM, TEM and FIB), the hypothesis that an addition of Mo to an Al-Si-Mg alloy (2L99) may alleviate the effect of double oxide film defects.

\section{EXPERIMENTAL PROCEDURE}

An experiment was conducted to trap an air bubble inside a liquid 2L99 alloy melt in a $16 \mathrm{~mm}$ diameter mild steel rod, with a $12 \mathrm{~mm}$ diameter and $40 \mathrm{~mm}$ deep blind hole at one end. During the experiment, $750 \mathrm{~g}$ of alloy was melted and held at a resistance furnace at $780{ }^{\circ} \mathrm{C}$. Then the steel rod (which preheated to $500{ }^{\circ} \mathrm{C}$ ) was immersed inside liquid aluminum to a depth of $90 \mathrm{~mm}$. The target temperature for the furnace was then set to $725^{\circ} \mathrm{C}$. The melt would take 5 minutes to reach target temperature $\left(725^{\circ} \mathrm{C} \pm 1{ }^{\circ} \mathrm{C}\right)$. The experimental setup has been shown in Figure 1. The oxide layer on the surface of the liquid were scraped off before immersion. However, a thin layer of oxide could still form and attach to the side of the steel rod, during the plunging process which would connect the entrapped air bubble to the outside atmosphere. To solve this problem, the steel rod was made to rotate at $90 \mathrm{rpm}$ during the plunging process and, after the steel rod was in the correct position inside the aluminum melt, a $6 \mathrm{~mm}$ steel rod was inserted into the aluminum melt, touching the rotating steel rod at the side, to break the leak path manually. The refractory coating was not used covering the sides of steel rod as the process of breaking the leak path (mechanical touching) would also remove those refectory materials.

The experiments were repeated twice to ensure reproducibility. Two experiment were conducted, with 2L99 and $2 \mathrm{~L} 99+0.4 \mathrm{wt}$ pet Mo respectively. Mo addition into 2L99 alloy was made by adding 2L99-8 wt pet Mo master alloy into the metal melt in the furnace. The master alloy was pre-made by adding pure Mo into 2L99 alloy at $1300{ }^{\circ} \mathrm{C}$ in a $4 \mathrm{~L}$ crucible charged by a 45 $\mathrm{kW}$ induction furnace, the metal melt was held at this temperature for $20 \mathrm{~min}$ for the dissolution of Mo.

After solidification, the area in the sketch, which labelled in Figure 1, was cut out for SEM examination. The morphology of the sample surface was compared, and the amount of metal drawn up into the blind hole (with a diameter of $12 \mathrm{~mm}$ and $40 \mathrm{~mm}$ deep) measured.

Castings were subsequently carried out with two sets of sand castings, each containing 30 testbars ( 3 molds, each mold contain 10 testbars), with the composition of 2L99 and 2L99+0.4 wt pct Mo, respectively. A sketch of the mold design has been shown in Figure 2, which shows a badly designed running system, which was top

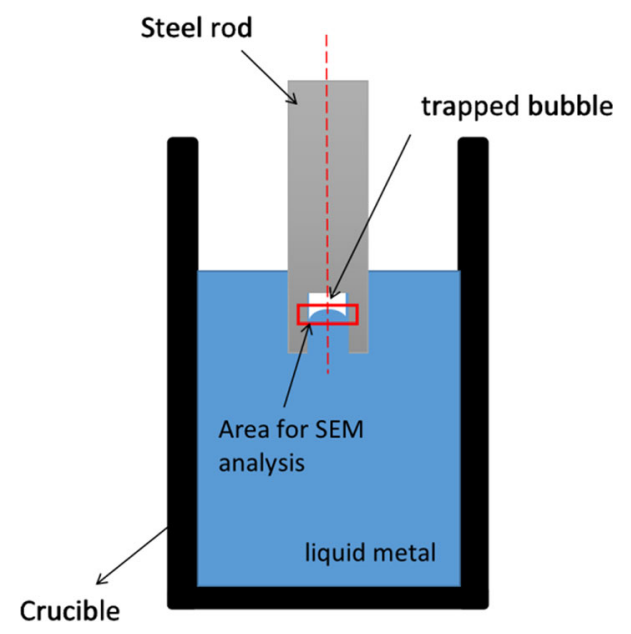

Fig. 1-Sketch of the experiment to trap an air bubble inside an aluminium melt for $1 \mathrm{~h}$. 


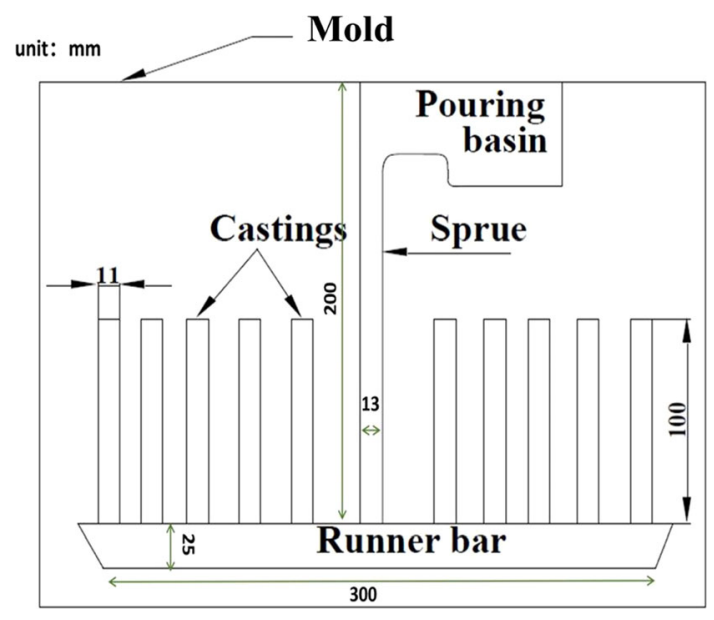

Fig. 2-The sketch of the mould used in the experiment for tensile testing. filled, and without a filter placed in the center of runner bar, expected to increase velocity and thus increase the turbulence of liquid metal. This may result in copious entrainment of double oxide film defects. For each groups of castings, $30 \mathrm{Kg}$ of 2L99 alloy were melted and held at $730{ }^{\circ} \mathrm{C}$ in an $90 \mathrm{~kW}$ induction furnace, before argon degassing for $20 \mathrm{~min}$ (Lance degassing, with 1.5 $\mathrm{L} /$ minutes argon introduction rate). The casting temperature was $725^{\circ} \mathrm{C}$. All three molds were quickly cast at one go after degassing, with all the molds filled in less than a minute. For the Mo addition castings, pre-made 2L99-8 wt pet Mo master alloy were added into the liquid metal in the holding furnace at $730{ }^{\circ} \mathrm{C}$ before $\mathrm{Ar}$ degassing. Immediately after casting, a section of the runner bar were cut for hydrogen content analysis with a $\mathrm{LECO}^{\mathrm{TM}}$ hydrogen content analyzer and chemical composition analysis.

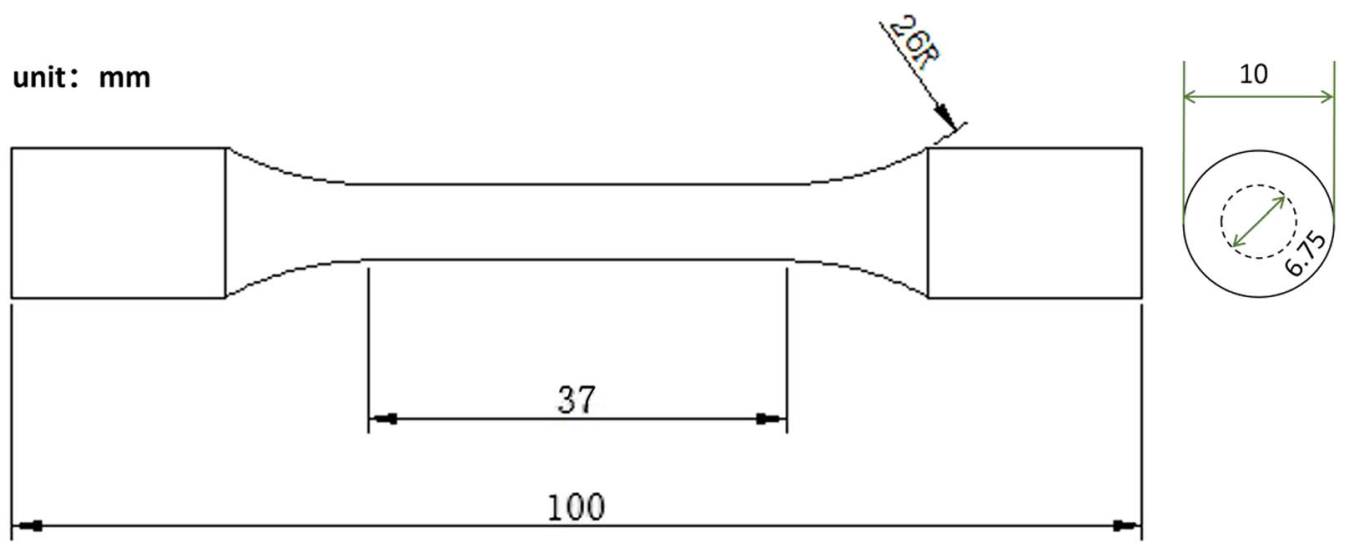

Fig. 3-Sketch of the test bar for tensile test of the sand castings.

Table I. The Initial Composition of the 2L99 Alloy Used in the Experiment

\begin{tabular}{llllllll}
\hline Elements & $\mathrm{Cu}$ & $\mathrm{Mg}$ & $\mathrm{Si}$ & $\mathrm{Fe}$ & $\mathrm{Mn}$ & $\mathrm{Ni}$ & $\mathrm{Zn}$ \\
\hline 2L99 ALLOY & & & & & & & \\
Weight Percent & 0.01 & 0.38 & 7.65 & 0.1 & 0.01 & 0.01 & 0.01 \\
Elements & $\mathrm{Zn}$ & $\mathrm{Pb}$ & $\mathrm{Sn}$ & $\mathrm{Ti}$ & $\mathrm{Mo}$ & $\mathrm{Al}$ & \\
Weight Percent & 0.01 & 0.01 & 0.01 & 0.1 & 0.0 & Bal. & \\
\hline
\end{tabular}

Table II. The Composition of 2L99/2L99 + Mo Alloy in Bubble Trapping Experiment and Sand-Casting Experiment

\begin{tabular}{|c|c|c|c|c|c|c|}
\hline \multicolumn{6}{|l|}{ Weight Percent } & ppm \\
\hline \multirow{4}{*}{ Bubble Trapping Experiment } & & Mo & $\mathrm{Fe}$ & $\mathrm{Mg}$ & $\mathrm{Ti}$ & $\mathrm{H}$ \\
\hline & 2L99 (Experiment I) & 0 & $0.71 \pm 0.04$ & $0.35 \pm 0.03$ & $0.13 \pm 0.02$ & \\
\hline & 2L99+ Mo (Experiment I) & $0.42 \pm 0.01$ & $0.68 \pm 0.03$ & $0.33 \pm 0.01$ & $0.11 \pm 0.01$ & \\
\hline & 2L99 (Experiment II) & 0 & $0.68 \pm 0.03$ & $0.37 \pm 0.02$ & $0.12 \pm 0.03$ & \\
\hline \multirow{3}{*}{ Sand Casting Experiment } & $2 \mathrm{~L} 99+$ Mo (Experiment II) & $0.39 \pm 0.03$ & $0.76 \pm 0.03$ & $0.35 \pm 0.01$ & $0.13 \pm 0.03$ & \\
\hline & 2L99 & 0 & $0.07 \pm 0.01$ & $0.36 \pm 0.01$ & $0.11 \pm 0.01$ & $0.127 \pm 0.016$ \\
\hline & $2 \mathrm{~L} 99+\mathrm{Mo}$ & $0.4 \pm 0.02$ & $0.06 \pm 0.02$ & $0.37 \pm 0.03$ & $0.10 \pm 0.01$ & $0.146 \pm 0.025$ \\
\hline
\end{tabular}


The testbars were machined with a gauge length of 37 $\mathrm{mm}$ and $6.75 \mathrm{~mm}$ Dia. The sketch of the tensile testbar was shown in Figure 3. The test was conducted with a Ziwick $^{\mathrm{TM}}$ tensile test machine equipped with a micro extensometer, with a pulling rate of $1 \mathrm{~mm} / \mathrm{min}$ (displacement control). The UTS and Pct Elongation for all the 60 testbars (2 groups) were recorded and fit into a two parameter Weibull distribution, with linear regression method.

The fracture surfaces, containing oxide layers forming double-oxide film defects in the 2L99 and 2L99+ Mo alloy tensile test bars, were examined using a field emission scanning electron microscope (SEM, JOEL $7000 \mathrm{~F}$ ), equipped with an energy-dispersive X-ray spectroscopy system (EDX, Oxford Instrument). Fracture surfaces of testbars were milled with a focused ion beam (FIB, FEI Quanta 3D) for cross-sectional observation. TEM samples of cross-sections of the nitride layers were fabricated by FIB milling, and then examined using an

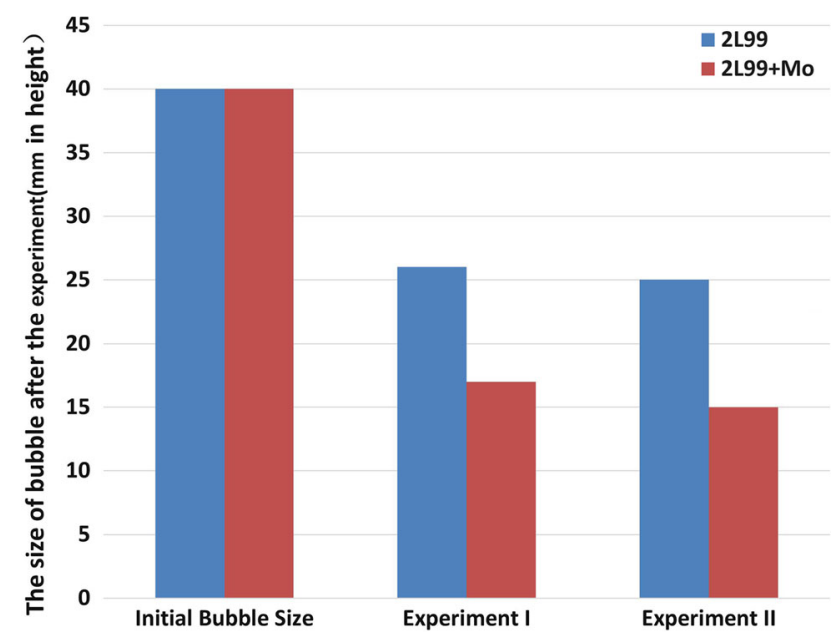

Fig. 4-The size of bubble after the bubble trapping experimen.

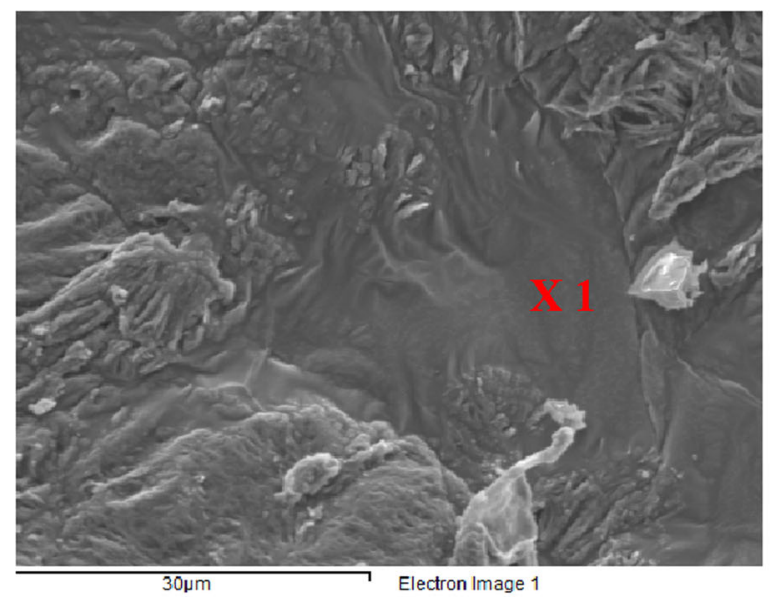

(a) in situ FIB lift-out technique for subsequent observation by a FEI Tecnai F20 TEM equipped with a scanning mode (STEM) and an EDX system.

The composition of the 2L99 alloy used in this experiment, has been shown in Table I. The main element pickup for 2L99 alloy and 2L99+ Mo alloy after the sand casting and bubble trapping experiments were shown in Table II (the pickup of $\mathrm{Fe}$ in bubble trapping experiment is due to dissolution of the Fe rod into the aluminum melt). All the measurements were repeated for five times by a Tiger S8 WDS-XRF. During the test, an $8 \mathrm{~mm}$ mask was used (with a detect area of $50.24 \mathrm{~mm}^{2}$ ) and the running time was 8 minutes.

\section{RESULTS}

\section{A. The Bubble Trapping Experiment}

A comparison of the reduction in bubble size in the experiment with 2L99 alloy and 2L99+ Mo alloy has been shown in Figure 4. As can be seen, the average remaining bubble size for 2L99 alloy and 2L99+ Mo alloy were $25 \mathrm{~mm}$ and $15 \mathrm{~mm}$ in height, respectively, which suggested that the Mo addition accelerated the consumption of the entrapped air in the liquid metal. The other factors such as density, fluidity or Capillary forces change by the addition of Mo might also have an effect on the bubble size.

SEM examination of the sample surface (Figure 5) showed that, for the experiment with 2L99 alloy, a continuous oxide layer on the sample surface was observed, and EDX analysis suggested that this oxide layer contained $\mathrm{Mg}$ and $\mathrm{O}$ in addition to $\mathrm{Al}$, suggesting the oxide might be $\mathrm{MgAl}_{2} \mathrm{O}_{4}$, (spinel), according to thermodynamic calculation. ${ }^{[19]}$ The presence of $\mathrm{Fe}$ was due to the dissolution of the iron rod into the liquid aluminum melt. However, for the 2L99+ Mo sample, (Figure 6), nitrogen was detected on the sample surface. The presence of nitride on the sample surface confirmed

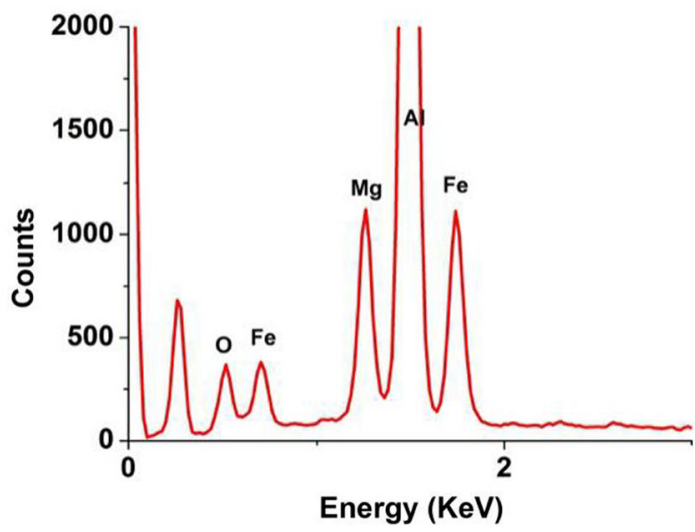

(b)

Fig. 5- (a) the SEM image of the sample surface of 2L99 alloy from bubble trapping experiment; (b) EDX analysis suggested that the surface layer consist of a uniform oxide laye. 


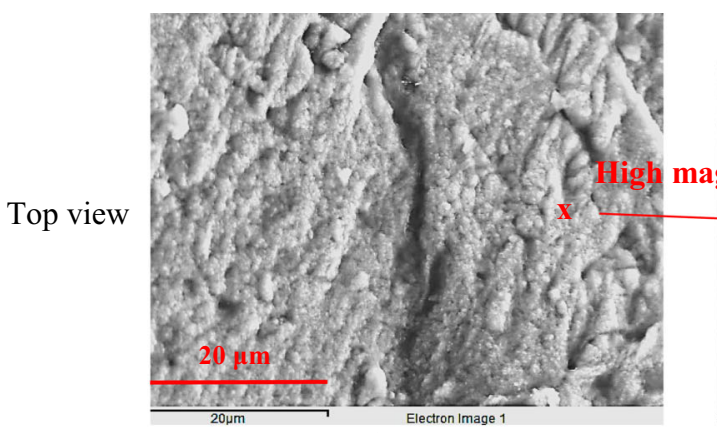

(a)

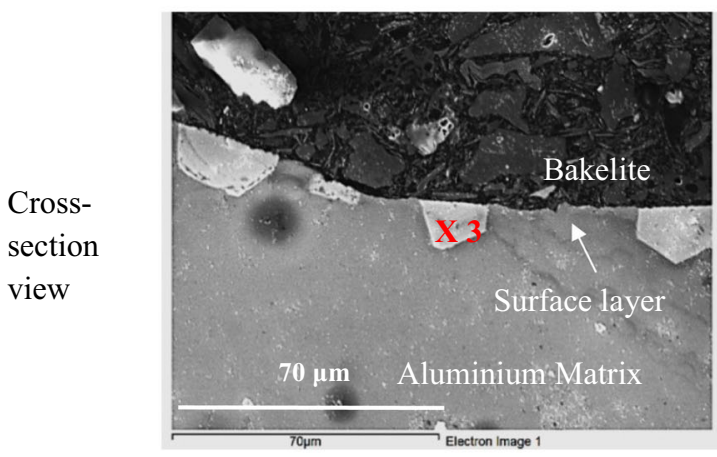

(c)

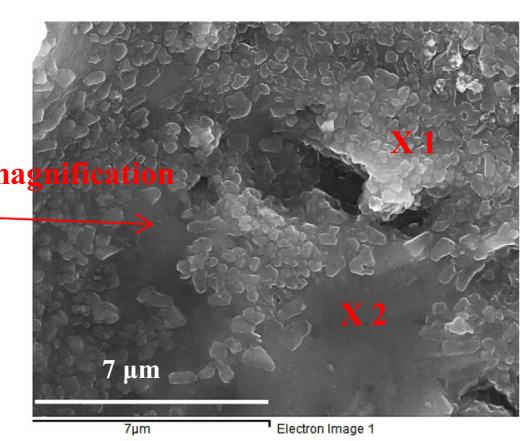

(b)

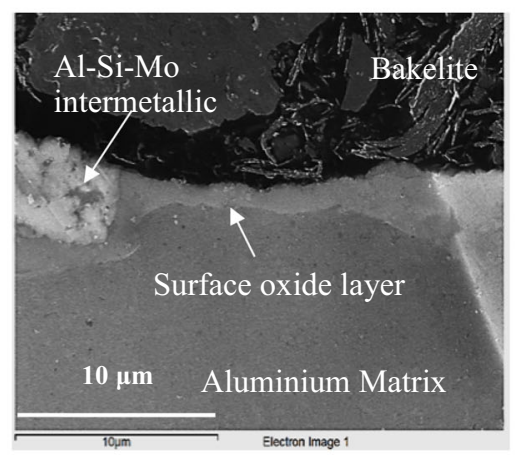

(d)

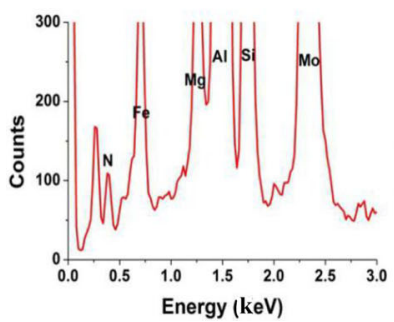

(e)

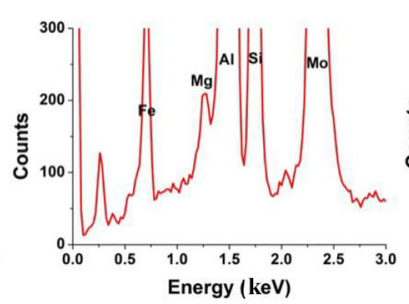

(f)

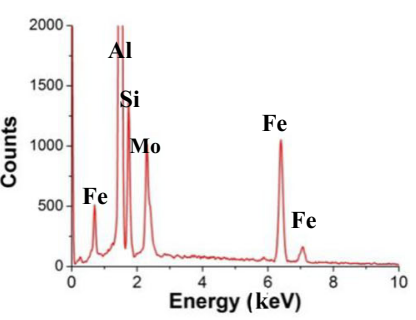

(g)

Fig. 6- (a) SEM image of the sample surface of 2L99+ Mo alloy from the bubble trapping experiment; $(b)$ is a higher magnification image from labelled X showing granular shaped nitride particles; $(c$ and $d$ ) are cross-sections of the surface layers of the sample showing the Mo-containing intermetallic compounds. (e) through $(g)$ are EDX spectrum of X1-X3 respectively.

Table III. Quantification of Spectra of Figures 4 and 5

\begin{tabular}{lccc}
\hline Description & $\begin{array}{c}\text { Fig. } 5 \times 1 \\
\text { 2L99 Continuous } \\
\text { Oxide Layer }\end{array}$ & $\begin{array}{c}\text { Fig. 6 x1 } \\
\text { 2L99+ Mo Particle on } \\
\text { the Surface }\end{array}$ & $\begin{array}{c}\text { Fig. 6 X2 } \\
\text { 2L99+ Mo Sample Surface Free } \\
\text { From Particles }\end{array}$ \\
\hline Weight Percent & $58.1 \pm 0.7$ & & \\
$\mathrm{Al}$ & $7.3 \pm 0.4$ & $50.9 \pm 0.9$ & $55 \pm 0.5$ \\
$\mathrm{Mg}$ & $10.9 \pm 0.6$ & $3.2 \pm 0.2$ & $0.2 \pm 0.1$ \\
$\mathrm{Si}$ & $7.6 \pm 0.4$ & $10.3 \pm 0.4$ & $10.6 \pm 0.3$ \\
$\mathrm{Fe}$ & 0 & $7.4 \pm 0.5$ & $18.0 \pm 0.4$ \\
$\mathrm{Mo}$ & 0 & $18.4 \pm 0.7$ & 0 \\
$\mathrm{~N}$ & $10 \pm 0.5$ & 0 & 0 \\
$\mathrm{O}$ & & 0 & $0.1 \pm 3.5$ \\
\hline
\end{tabular}

that the majority of the oxygen in the entrapped atmosphere will have been consumed, as AlN can only be formed when the oxygen concentration in the bubble falls below about 5 Vol pct (estimated by Raeiszadeh). ${ }^{[12]}$
Images of the surface from the $2 \mathrm{~L} 99+0.4 \mathrm{wt}$ pct Mo sample has been shown in Figures 6(a) and (b), which suggested that the sample surface consisted of nitride containing particles. Figure 6(b) is a higher 


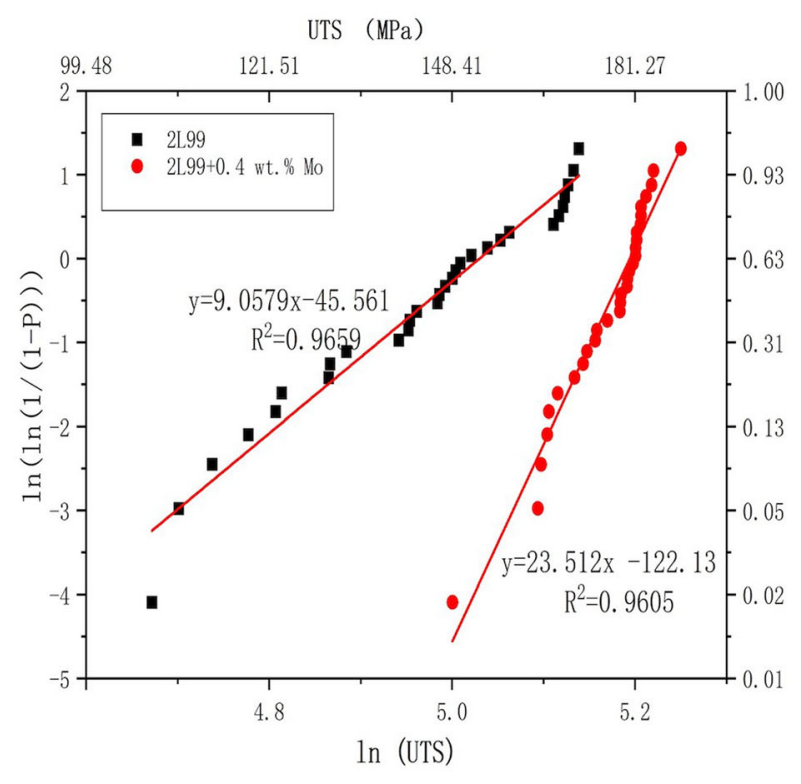

(a)

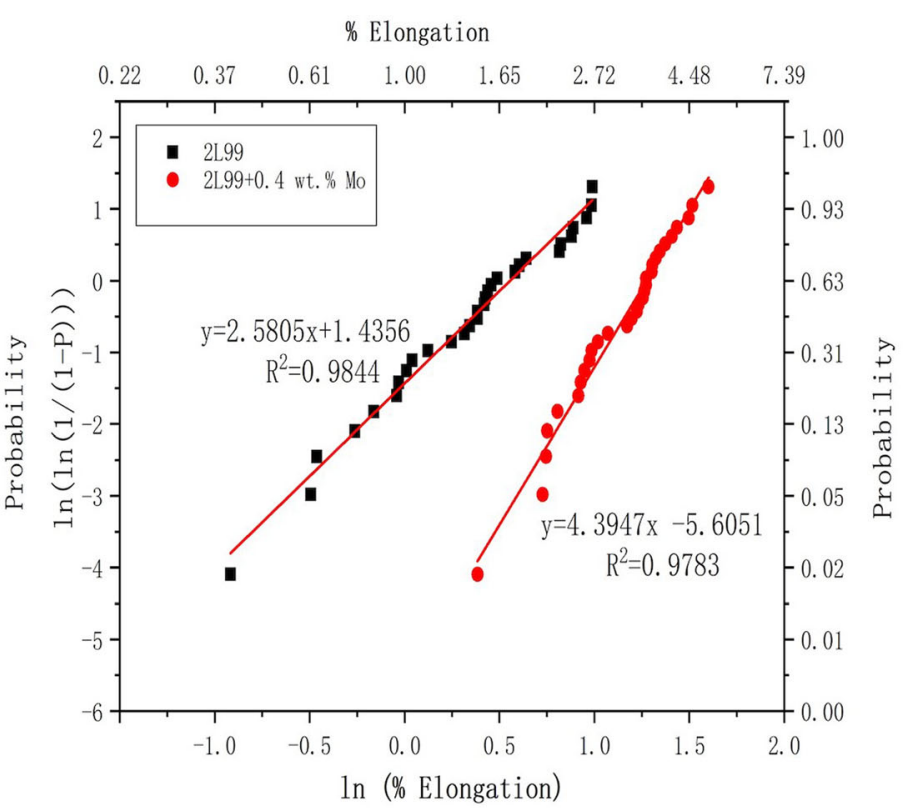

(b)

Fig. 7-Weibull plot for (a) UTS and (b) \%Elongation for 2L99 and 2L99+0.4 wt pct Mo.

magnification image of the point labelled X in Figure 6(a). EDX for this point has been shown in Figure 6(e), which suggested the particles were nitrides of a size of around 500 $\mathrm{nm}$, dispersed discontinuously on the sample surface. The EDX spectra shown in Figure 6(f), taken from location X2 where nitride particles were absent, did not show nitrogen. This discontinuous surface layer might provide a convenient site for the consumption of the entrapped gas in the bubble by the surrounding liquid metal. Mo were detected in all three spectra, $\mathrm{X} 1$, where $\mathrm{N}$ was reported, $\mathrm{X} 2$ where $\mathrm{N}$ was absent, and X3 (Figure 6(g)), taken from a cross-section of an intermetallic (containing Al-Si-Fe-Mo). Therefore, it is possible that the Mo peak came from Mo-containing intermetallic compounds beneath the surface. A cross-section milled from the sample surface showed that the Al-Si-Fe-Mo intermetallic compound was associated with a surface film. The quantification of the spectra for Figures 5 and 6 are shown in Table III. Fe dissolved in the liquid metal might be present as $\mathrm{Fe}$ containing intermetallic compound $(\alpha-\mathrm{A} 18 \mathrm{Fe} 2 \mathrm{Si}$, $\beta$-A15FeSi and $\pi$-A18Mg3FeSi6), which were commonly observed in Al-Mg-Si alloy ${ }^{[20]}$ or Al-Si-Mo-Fe intermetallic compound as shown above.

\section{B. The Sand-Casting Experiment}

Tensile testbars cast using the mold design shown in Figure 2 were used to determine the Weibull plots for the UTS and Pct Elongation of the castings with Mo additions (shown in Figure 7) and summarized in Table V. A two-parameter Weibull distribution with linear regression method were used to fit the data set. The probability of failure was unknown and was estimated based on the following equation:

$$
\mathrm{P}=\frac{n_{i}-0.5}{n_{\text {total }}+0.25}
$$

where $n_{i}$ is the sample ranking and $n_{\text {total }}$ is the total number of testbars in the group.

As can be seen from Table $\mathrm{V}$, the addition of 0.4 wt pct Mo showed a 20 pct increase in mean value of the UTS while the values for Pct Elongation was doubled compared with 2L99 alloy without addition

The $R^{2}$ value was used to assess the goodness of fit for the data set. ${ }^{[21]}$ The data set for the UTS and \%Elongation can only be accepted as following a Weibull distribution if $R^{2}>R_{0.5}^{2}$, where $R_{0.5}^{2}$ can be written as:

$$
R_{0.5}^{2}=1.0637-\frac{0.4174}{n^{0.3}}
$$

The $R^{2}$ values for the plots are shown in Table IV and were all higher than $R_{0.5}^{2}(n=30)$, which suggested that all the plots can be accepted as having Weibull distributions.

A statistical method was then used to compare the Weibull Moduli of the two castings (i.e., the shape parameters) with the help of a Monte-Carlo simulation. ${ }^{[22]}$ Two data sets with sample size $n_{1}$ and $n_{2}$ respectively, where $\left(n_{1}>n_{2}\right)$ was generated following a Weibull distribution with a shape parameter $m=1$ and scale parameter $\sigma=3$. The Weibull moduli of each data set was then estimated using a linear regression method to obtain an estimated value $m_{1}$ and $m_{2}$, respectively. The value $m_{1} / m_{2}$ was recorded and this process was repeated for 100,000 times. The 2.5 and 97.5 percentiles were recorded. 
Table IV. Criteria for Weibull Distributions ${ }^{\text {[21, 22] }}$

\begin{tabular}{lccccc}
\hline & \multicolumn{2}{c}{ UTS } & & \multicolumn{2}{c}{ Percent Elongation } \\
\cline { 2 - 3 } & 2L99 & 2L99 +0.4 Weight Percent Mo & & 2L99 & 2L99 + 0.4 Weight Percent Mo \\
\hline $\mathrm{R}_{0.5}^{2}$ (30 samples) & 0.91 & 0.96 & & 0.98 & 0.98 \\
$R^{2}$ & 0.97 & Yes & Yes & Yes \\
Accepted as Weibull Distribution & Yes & & & \\
\hline
\end{tabular}

Table V. Summary of the Tensile Test Results

\begin{tabular}{|c|c|c|c|c|}
\hline & \multicolumn{2}{|r|}{ UTS (MPa) } & \multicolumn{2}{|r|}{ Percent Elongation } \\
\hline & 2L99 & 2L99+0.4 Weight Percent Mo & 2L99 & $2 \mathrm{~L} 99+0.4$ Weight Percent Mo \\
\hline Position Parameter (Scale Parameter) $\mathrm{MPa}$ & 152.9 & 180.3 & 0.57 & 3.58 \\
\hline Weibull Moduli (Shape Parameter) & 9.1 & 23.5 & 2.6 & 4.4 \\
\hline $\mathrm{m}_{1} / \mathrm{m}_{2}$ & 2.58 & & 1.69 & \\
\hline 2.5,97.5 Percentile & $0.596,1.677$ & & & \\
\hline Significant Different in Weibull Moduli & Yes & & Yes & \\
\hline Mean Value & 144.6 & 176 & 1.54 & 3.2 \\
\hline
\end{tabular}

The ratio of the Weibull moduli of the UTS and Pct Elongation of the 2L99 alloy castings, with and without Mo additions, were recorded and if this value fell between the 2.5 and 97.5 percentiles, then the two data set were assumed to be similar. However, if this value fell outside the percentile range then a significant difference existed between the two data sets. The Weibull Moduli comparison has been shown in Table V. As can be seen, the Weibull Moduli for both UTS and Pct Elongation showed significant improvement with the addition of $0.4 \mathrm{wt}$ pct Mo. In addition, the mean value for UTS and Pct Elongation were improved by 22 pct and 108 pct, respectively.

\section{The Comparison of the Structure and Morphology of Double Oxide Film Defects in 2 L99 Alloy and 2L99+ Mo Alloy Castings}

Double oxide film defects on the fracture surface of 2L99 alloy castings (with and without the addition of Mo) were analyzed by SEM, and TEM with the help of Focus Ion beam milling (FIB).

Figures 8(a) and (b) shows a double oxide film defect symmetrically located on both sides of a fractured tensile testbar (2L99 alloy), revealing the doubled nature of the defect (with each fracture surface contain one of the oxide film from the defect). EDX analysis of the surface (Figure $8(\mathrm{~g})$ ) showed that the composition of the oxide layer consisted of a small oxygen peak in addition to $\mathrm{Al}, \mathrm{Mg}$ and $\mathrm{Si}$ peaks, which suggested a layer of spinel $\left(\mathrm{MgAl}_{2} \mathrm{O}_{4}\right)$. A high magnification image of the oxide layer (magnified by 120,000 times) has been shown in Figure $8(\mathrm{~d})$, showing that the oxide film consisted of oxide particles, of size of around $80 \mathrm{~nm}$. Smaller oxide particles, possibly 10 to $20 \mathrm{~nm}$ in size, were also seen, occurring between the larger particles. Figures 8(e) and (f) were cross-section view of a tangled bifilm defect, with oxide particles on the unwetted side of bifilm.

Figure 9 showed a typical oxide from a bifilm defect discovered on the fracture surface of a 2L99+ Mo casting. Unlike the oxide film found on a 2L99 alloy casting, which contained a small oxygen peak (Figure $8(\mathrm{~g}))$, the oxide found here contained a high oxygen peak (Figure 9(c)). The high magnification image of the oxide layer suggested that the surface layer consisted of oxide particles of about 2 to $3 \mu \mathrm{m}$ (Figure 9(b)), which were much larger than the oxide particles found in the 2L99 alloy casting (which were about $80 \mathrm{~nm}$ ). EDX analysis showed that, in this example, the oxide from the 2L99 + Mo alloy contained 55 wt pet oxygen, which was about five times higher than the oxide from 2L99 alloy (which contained $10 \mathrm{wt}$ pct of oxygen), suggesting a thicker oxide with the addition of Mo (X2 showed an Al-Si-Mo intermetallic compound on the sides of the oxide layer).

Figures 10, 11, 12, 13 showed three different morphology of nitride containing bifilm observed on the fracture surfaces of a 2L99 alloy modified with $0.4 \mathrm{wt}$ pet Mo addition, which occupied 20 pet of the testbars. Figure 10(a) showed, the morphology of the bifilm in low magnification on the fracture surface of a testbar to be no different from the oxide found in the 2L99 alloy without Mo, (Figure 8(a)), except its lighter contrast. However, the SEM image in (Figure 10(c)) showed a tooth-shaped morphology on the sample surface, and EDX analysis (Figure 10(d)) detected a nitrogen peak, in addition to an oxygen peak, suggesting an oxide/ nitride layer. Focused Ion Beam milling was used to obtain a cross-section of this area, showing this tooth-shaped nitride layer to be permeable and of 


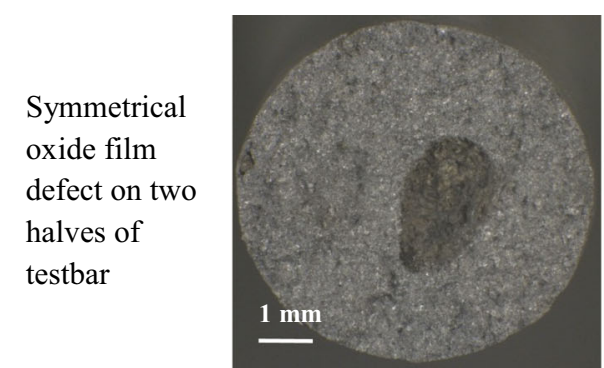

(a)

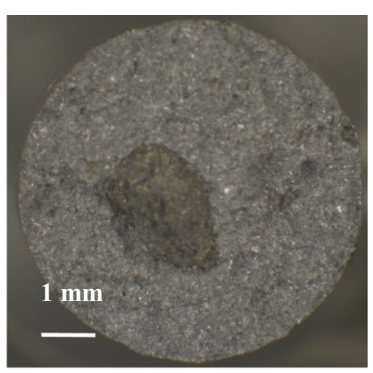

(b)

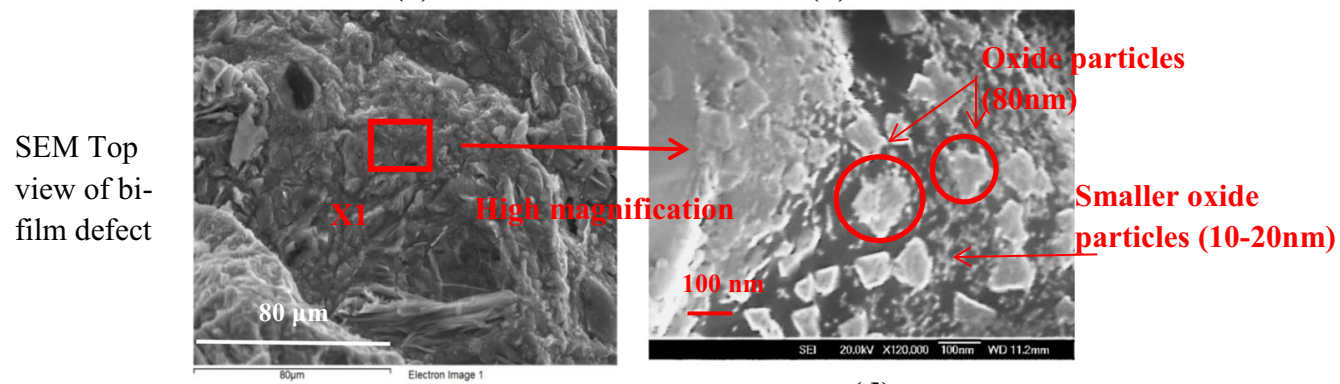

(c)

(d)

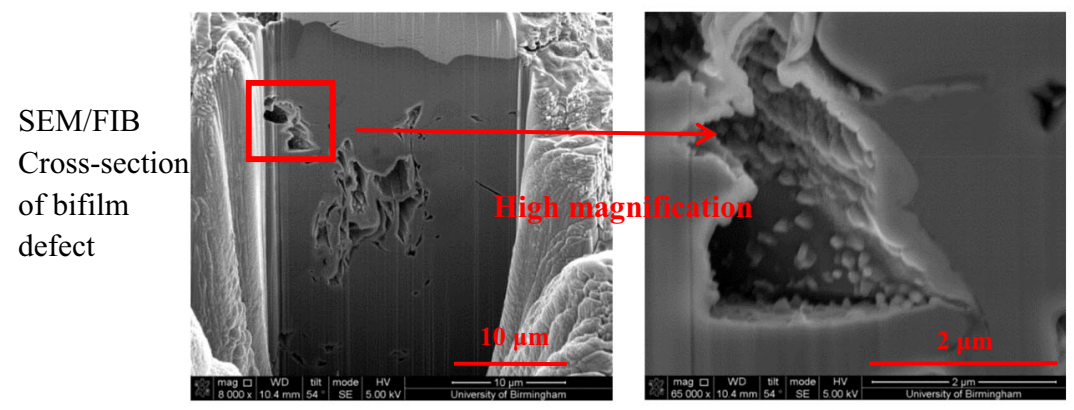

(e)

(f)

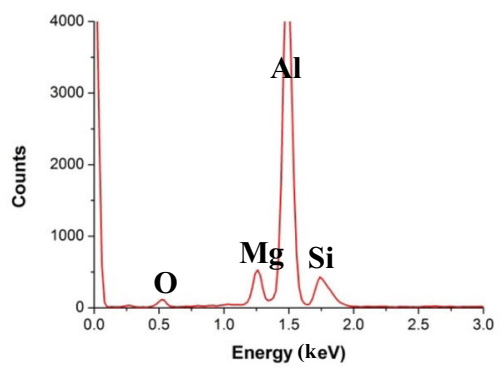

(g)

Fig. 8- $(a)$ and $(b)$ symmetrical double oxide film defect on the two halves of fracture surface of 2L99 cast testbar; $(c)$ and $(d)$ SEM image of the un-wetted side bifilm; $(e)$ and $(f)$ cross-section of the bi-film defect; $(g)$ EDX spectrum of X1.

thickness of around $4 \mu \mathrm{m}$. A similar permeable nitride layer was also seen by Gerrard,15 in an experiment in which pure liquid aluminum was held under a nitrogen atmosphere for $15 \mathrm{~min}$ ).

Figure 11(a) shows the morphology of a nitride containing bifilm defect from the fracture surface of another testbar of 2L99+ Mo casting. EDX analysis of Figure 11(a) xl suggested strong $\mathrm{O}$ and $\mathrm{Mg}$ peaks, suggesting spinel, and a weak $\mathrm{N}$ peak (Figure 11(e)). A nearby area (Figure 11(b) x2), however, showed particles where a high nitrogen content was detected (shown in Figure 11(f), compared with x1), but no Mg peak was detected. These nitride particles, typically 1 to $2 \mu \mathrm{m}$ in sizes, were also seen by FIB milling of the cross-section of the area (Figures 11(c) and (d)). This suggested that the area may have been a mixture of nitride particles and spinel whiskers.

Figure 12(a) showed a nitride-containing bifilm defect found on the fracture surface of another testbar in Mo-modified 2L99 alloy, with thickness of $33 \mu \mathrm{m}$ of an oxide/nitride layer. To better understand the morphology and structure of this nitride-containing layer, a TEM sample was fabricated. The analysis was mainly focused on two parts, the wetted side and the unwetted 


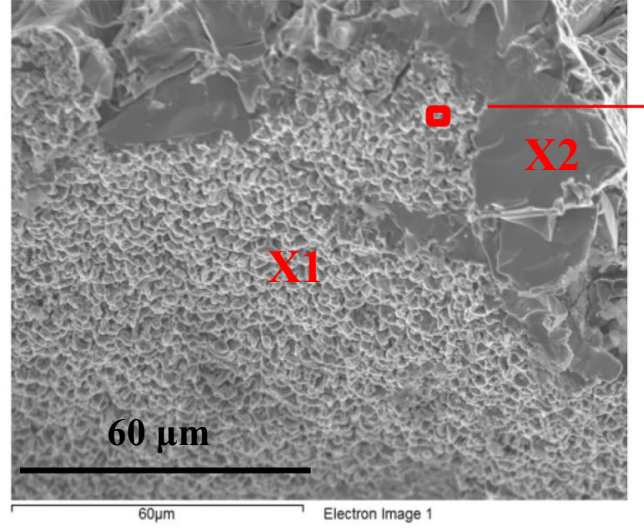

(a)

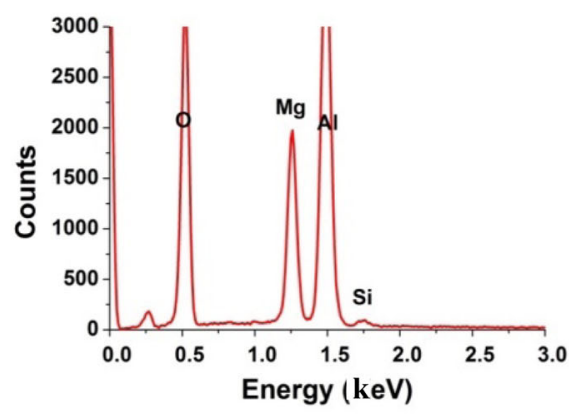

(c)

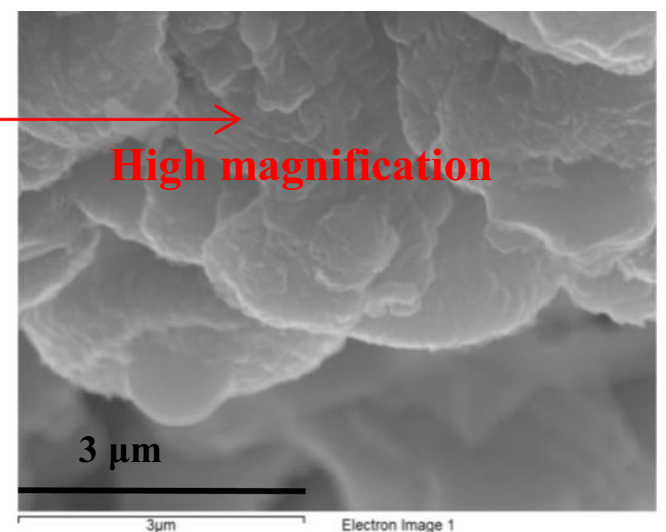

(b)

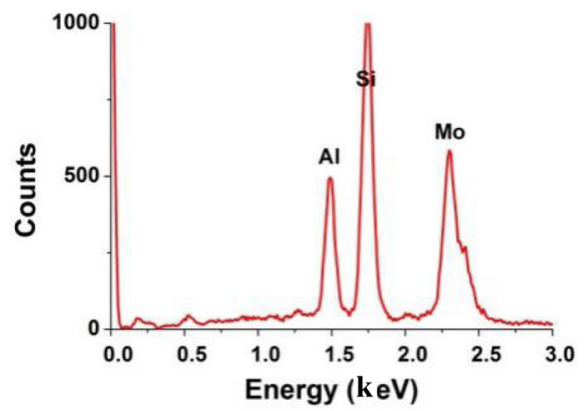

(d)

Fig. 9- (a) oxide from a bifilm defect discovered on the fracture surface of 2L99+ Mo alloy with Ai-Si-Mo intermetallic compounds on the side; (b) high magnification image of the oxide particles; $(c)$ and $(d)$ are EDX spectrum of $\mathrm{x} 1$ and $\mathrm{x} 2$ respectively.

side of the layer. The wetted side of the film refers to the side in contact with Al matrix, while the unwetted side of the layer refers to the area in contact with the entrapped atmosphere (shown in Figure 12(c)). Figure 13(a) showed the wetted side of the bifilm where a nitride layer, consisting of particles 2 to $3 \mu \mathrm{m}$ in size may have formed directly in contact with the aluminum matrix. EDX mapping suggested that the particles were very likely AlN (A strong image of $\mathrm{Al}$ and $\mathrm{N}$ were discovered, while the image for $\mathrm{O}$ were weak). Figure 13(b) formed on the unwetted side of the bifilm defect, (Figure 13(b); location X2), showed that this area contained a mixture of very fine particles (in the central part, as labeled in Figure) and whiskers (on the two sides, as labeled in Figure). TEM EDX analysis suggested that this area contained high oxygen, magnesium and aluminum peaks, and was possibly spinel. TEM analysis suggested that the nitride-containing layer may have consisted of two parts, with nitride particles formed on the wetted side of the bifilm while spinel whiskers/fine particles occurred on the unwetted side.

Mo was not seen to directly precipitate during the formation of oxides or nitrides in the bifilm defect in the 2L99 + Mo casting. However, an Al-Mo-Si intermetallic compound was seen on the bifilm, shown in Figure 14(a). The composition of the intermetallic compound was confirmed by EDX and has been shown in Table VI, which possibly be $\mathrm{MoSi}_{2}$, with a small proportion of $\mathrm{Al}$ taking the $\mathrm{Si}$ site. These intermetallic compounds are variable in size ranging from tens of $\mu \mathrm{m}$ to a few hundred $\mu \mathrm{m}$ (Labeled in Figure 14(a)).

\section{DISCUSSION}

Impey ${ }^{[18]}$ suggested that a $\mathrm{Mg}$ content in an $\mathrm{Al}-\mathrm{Mg}$ alloy of between 0.15 and $1.5 \mathrm{wt}$ pct the most thermodynamically favored product of the reaction between the aluminum melt and oxygen should be $\mathrm{MgAl}_{2} \mathrm{O}_{4}$. As the $\mathrm{Mg}$ content in the $2 \mathrm{~L} 99$ alloy was $0.35 \mathrm{wt}$ pct, the oxide probably formed should probably be spinel $\left(\mathrm{MgAl}_{2} \mathrm{O}_{4}\right)$. This was also confirmed by Belistku et al.23, 24, who suggested that in an Al-Mg alloy melt with a Mg content of 3 to $4 \mathrm{wt}$ pct, the initial oxide layer should be $\mathrm{MgO}$. However, as the oxide layer thickens and the $\mathrm{Mg}$ was consumed, for a $\mathrm{Mg}$ content of $<1 \mathrm{pct}$, the oxide formed would be spinel. ${ }^{[25]}$

Despite the continuous appearance of the oxide layer on the 2L99 alloy, as shown in Figures 8(a) through (c), small oxide particles (about 20 to $80 \mathrm{~nm}$ ) were seen on the sample surface at $\times 120,000$ using an SEM. A number of researchers ${ }^{[19,26]}$ have suggested that, for an Al-Mg alloy, the original oxide formed would be in an amorphous stage, which oxide might then be transformed into crystalline spinel (as $\mathrm{MgAl}_{2} \mathrm{O}_{4}$ ). The phase transformation and the in-homogeneous growth of the 


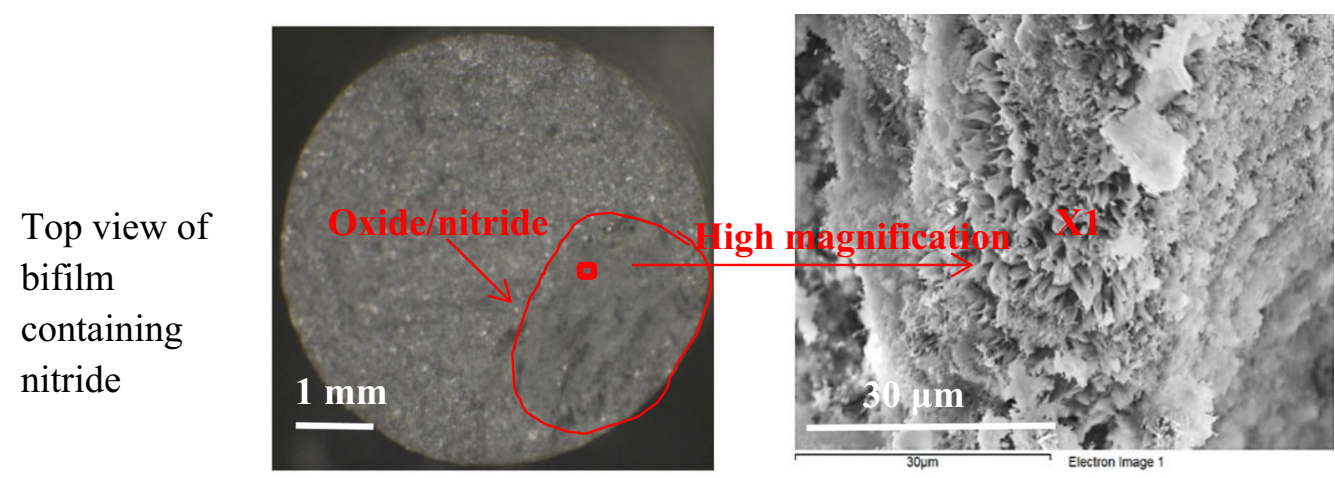

(a)

(b)

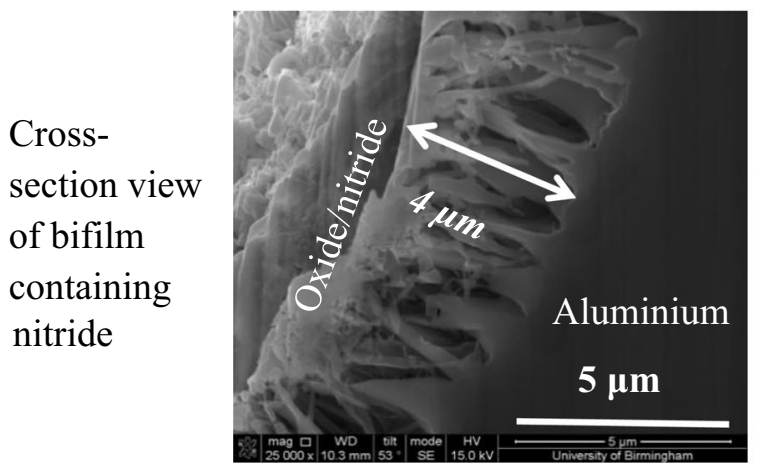

(c)

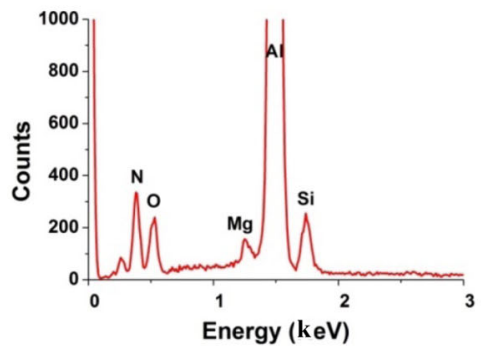

(d)

Fig. 10-Bifilm defect on the fracture surface of 2L99+ Mo alloy; $(a)$ and $(b)$ are low and high magnification of the oxide/nitride layer respectively; $(c)$ is a cross-section view of the oxide/nitride layer of (b) consisting of tooth shaped nitride; (d) is the EDX spectrum for X1.

spinel particles might introduce stress within an oxide layer, which could be initiation sites for cracks, resulting in liquid metal penetrating through the oxide layer and reacting with the entrapped atmosphere in a bifilm. Such cracks could also be formed by movement of double oxide film defect in the liquid metal. The oxide particles observed in this work may be in the crystalline state formed as a result of oxidation from an amorphous state. As the oxidation process going on, the oxide particles would increase in size and quantity with a continuous transmission of metal ions and gas through the bifilm structure. The oxide particles would eventually have formed a continuous layer and the oxide layer would be few hundreds or microns thick. The entrapped air would also consumed gradually during the time and the overall size of the defect would be reduced.

However, the consumption of the oxygen part of the entrapped atmosphere may not have a significant effect on bifilm size and morphology in 2L99 alloy, (although Raiszadeh and Griffiths suggested a relative rate of consumption of $\mathrm{O}$ and $\mathrm{N}$ that was about $50 \mathrm{pct}^{[12]}$ ). Since nitride was not widely seen on the fracture surfaces examined this indicated that any bifilms studied should still be in their oxygen consumption stage. Therefore, there may not be significant change in the size of a bi-film defect due to the consumption of its' interior atmosphere and the mechanical properties of the tensile test bars, in turn, may not be significantly affected.

The addition of Mo into 2L99 alloy castings resulted in a fracture surface that was modified in comparison with that of a bifilm defect. Instead of a continuous spinel layer, typically found on the fracture surface of 2L99 alloy castings, nitride containing particles were found between the aluminum matrix and the spinel layer when the alloy melt was modified with Mo (Figures 10(c), 11(d) and 13(a)). The spinel were also found to be porous (Figures 11(a) and 13(b)). The porous structure (which contains both oxide and nitride) was thought to be the key reason leading to the quicker consumption of the entrapped atmosphere, although, at this stage, the exact mechanism is still unknown. The entrapped atmosphere would be transmitted through the porous spinel layer more easily than through the typical spinel of 2L99 alloy and formed initially new spinel (particles/whiskers) and then a layer of nitride particles on the interface between the Al matrix and the original spinel layer, while the majority of $\mathrm{O}$ was consumed. The newly formed nitride particle would push the spinel to one side, which formed the duplex layer, (as shown in Figures 11, 12, 13). The process was summarized in Figure 14. 


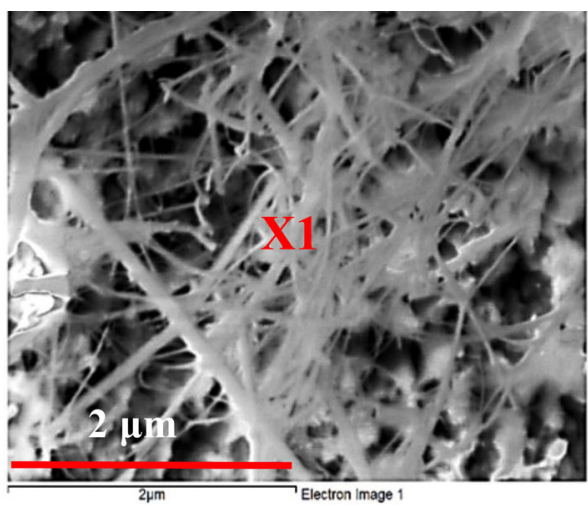

(a)

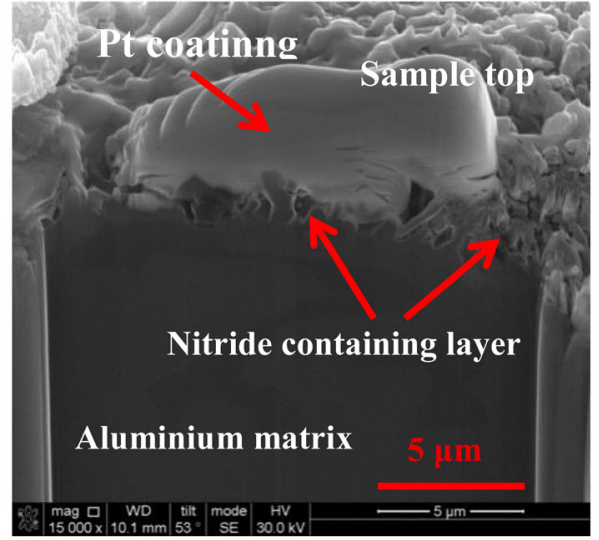

(c)

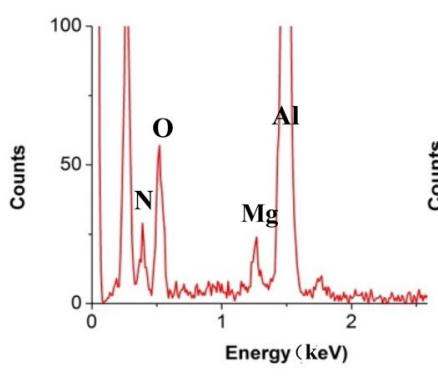

(e)

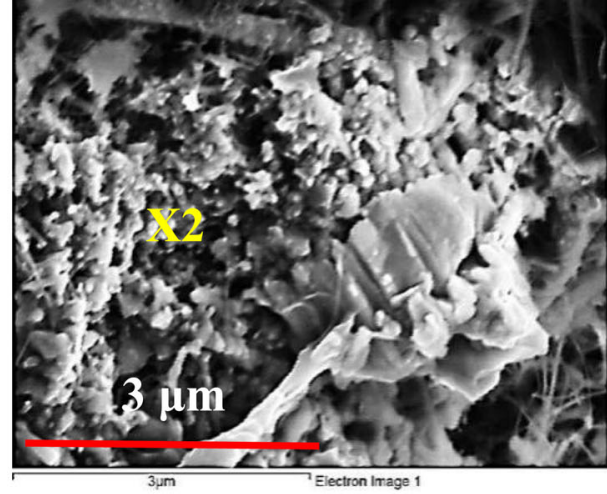

(b)

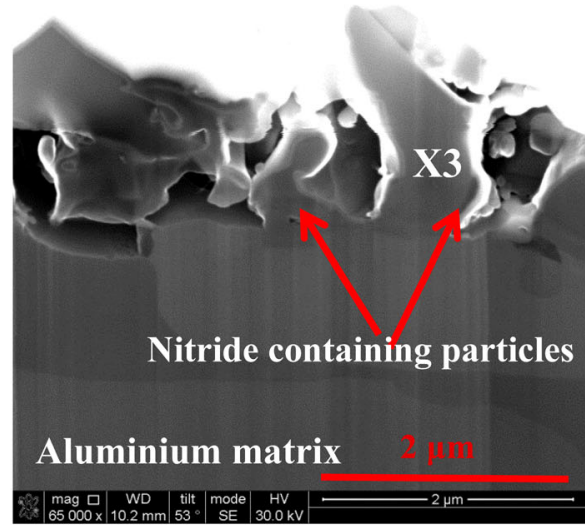

(d)

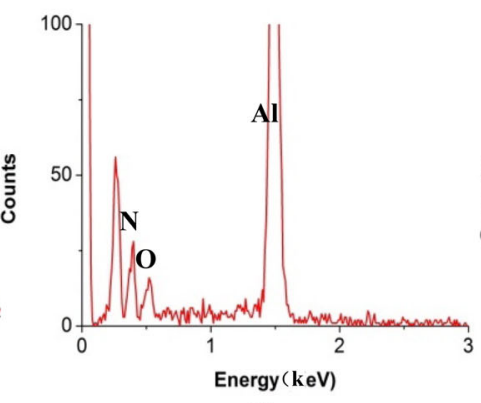

(f)

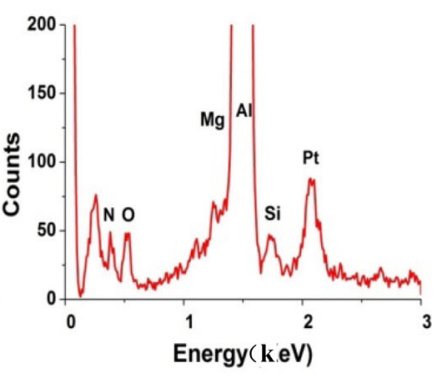

(g)

Fig. 11 - Oxide/nitride layer in a bifilm defect from 2L99+ Mo castings; showing whiskers oxide on the unwetted (a) and nitride containing particles in the wetted side $(b) ;(c)$ and $(d)$ are cross-section of the nitride containing layers from the bifilm; $(e)$ through $(g)$ are EDX spectrum of $\mathrm{x} 1-\mathrm{x} 3$ respectively.

Although Mo was not found to directly affect the morphology or composition of an oxide (or nitride) forming part of a double oxide film defect, Al-Mo-Si intermetallic compounds were discovered on the fracture surfaces. They were mostly discovered associated with bifilm defects (e.g., Figures 6(a), 9(a) x2 and 14(a)) and they were observed as particles with different sizes, between 20 and $100 \mu \mathrm{m}$ (Figure 14(a)). These intermetallic compounds may play a role in altering the structure of the bi-film defect (Fig. 15).
The wetted side of a bifilm defect might be an ideal substrate for the nucleation of $\mathrm{Mo}(\mathrm{Si}, \mathrm{Al})_{2}$ intermetallic. The calculation for the lattice mismatch between $\mathrm{Mo}(\mathrm{Si}, \mathrm{Al})_{2}$ and $\mathrm{MgAl}_{2} \mathrm{O}_{4}$ (proposed by Bramfitt ${ }^{[28]}$ ) were shown in Table VII. The best three lattice misfit was shown in the Table, which were all $<10$ pct, among which the lattice mismatch for $[111] \mathrm{MgAl}_{2} \mathrm{O}_{4} / /[100] \mathrm{Mo}(\mathrm{Si}, \mathrm{Al})_{2}$ was only -0.6 pet (for $\mathrm{Mo}(\mathrm{Si}, \mathrm{Al})_{2}$ growing on $\mathrm{MgAl}_{2} \mathrm{O}_{4}\{-1,1,0\}$ ), suggesting that the nucleation was most likely to 


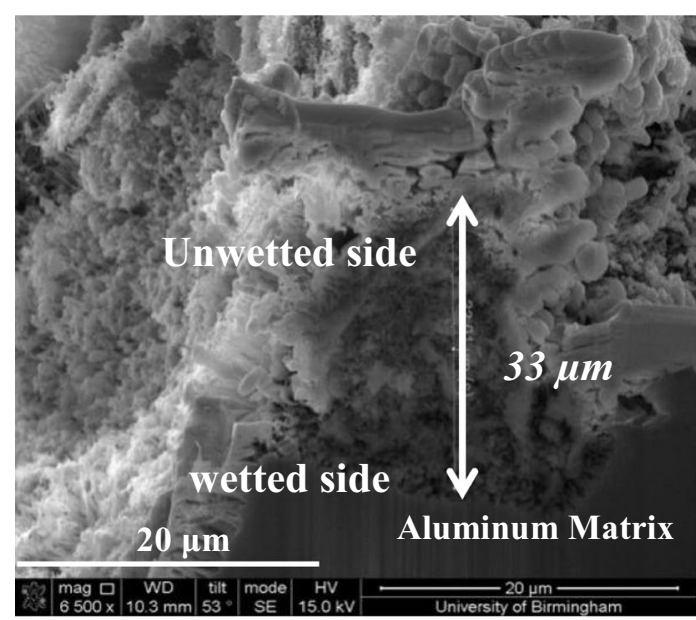

(a)

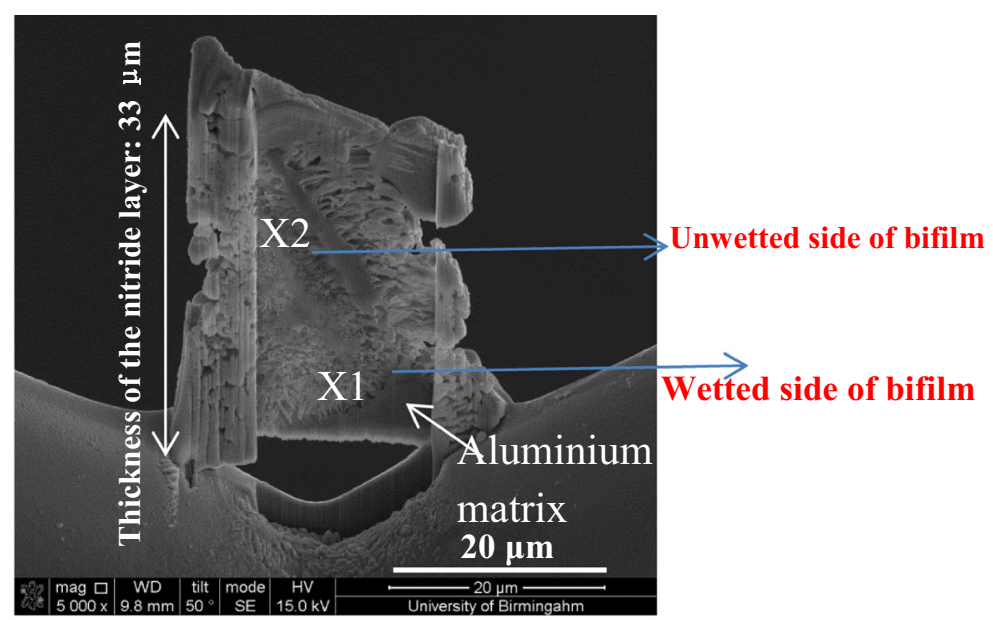

(b)

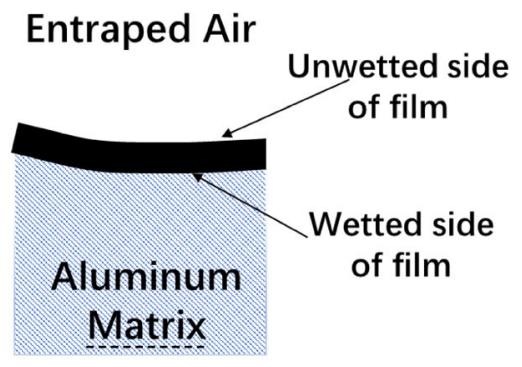

(c)

Fig. 12- $(a)$ and $(b)$ TEM sample of a nitride layer discovered on a nitride containing fracture surface from 2L99+ Mo alloy, prepared by FIB with lift out technology; $(c)$ Explanation to the wetted side and unwetted side of oxide/nitride film.

occur. Figure 6(c) showed the cross-section view of the oxide/nitride layer in the bubble trapping experiment with Al-Si-Mo intermetallic on the side. A similar situation was also seen on Figures 9(a) and Figure 14(b) on the fracture surfaces of 2L99 alloy modified with Mo.

Guo et al. ${ }^{[27]}$ assessed the Al-Mo-Si phase diagram and suggested that $\mathrm{Mo}(\mathrm{Al}, \mathrm{Si})_{2}$, could start to form at a temperature higher than $800{ }^{\circ} \mathrm{C}$, and could be stable until $550{ }^{\circ} \mathrm{C}$ (for Al-7.5 wt pet Si-0.4 wt pet Mo), which could cover the entire temperature range for metal holding and solidification. This means that the intermetallic compound could start nucleating and growing on the sides of a bifilm as long as the Mo was added to the melt. The nucleation and growth of the intermetallic compounds would introduce stress to the oxide layer, leading to its rupture and the consumption of the entrapped atmosphere.

A rupture in the oxide film, (which might have many causes), or the permeability of the oxide or the nitride film, would each promote the reaction between the liquid metal and the entrapped atmosphere. The permeability would also allow hydrogen to more easily diffuse into the interior of a bifilm, which might increase the size of the bifilm defects. (A significant increase in hydrogen diffusion rate through a nitride layer, compared to an oxide layer, was discovered by Gerrard and Griffiths ${ }^{[15]}$.

Whether the rate of inflation of double oxide film defects by diffusion of $\mathrm{H}$ can be outweighed by the rate of gas consumption probably would depend on the size and nature of any fractures in the oxide film defects and the hydrogen content in the liquid.

To summaries, high magnification observations of the surfaces of the trapped bubble experiments, and fracture surfaces of cast testbars confirmed earlier suggestions ${ }^{[8]}$ that oxide film defects can be reduced in their detrimental effects by consumption of their interior atmosphere. However, the variable nature of the constituents of the bifilms, for example, the particle size in the oxide film, permeability of the nitride layer, and its variation in thickness, would all make for a variation in the rate of gas flux through an oxide film wall. This would be dependent on four things; (i). the rate of reaction of the interior atmosphere with the surrounding melt, (ii). the diffusion of $\mathrm{H}$ in solution in the melt through the oxide film into the entrained atmosphere and, (iii), the nucleation of intermetallics, possibly on oxide films, and by inference, therefore, on nitride films also, (due to their similar lattice mismatch), and, (iv). transmission of 


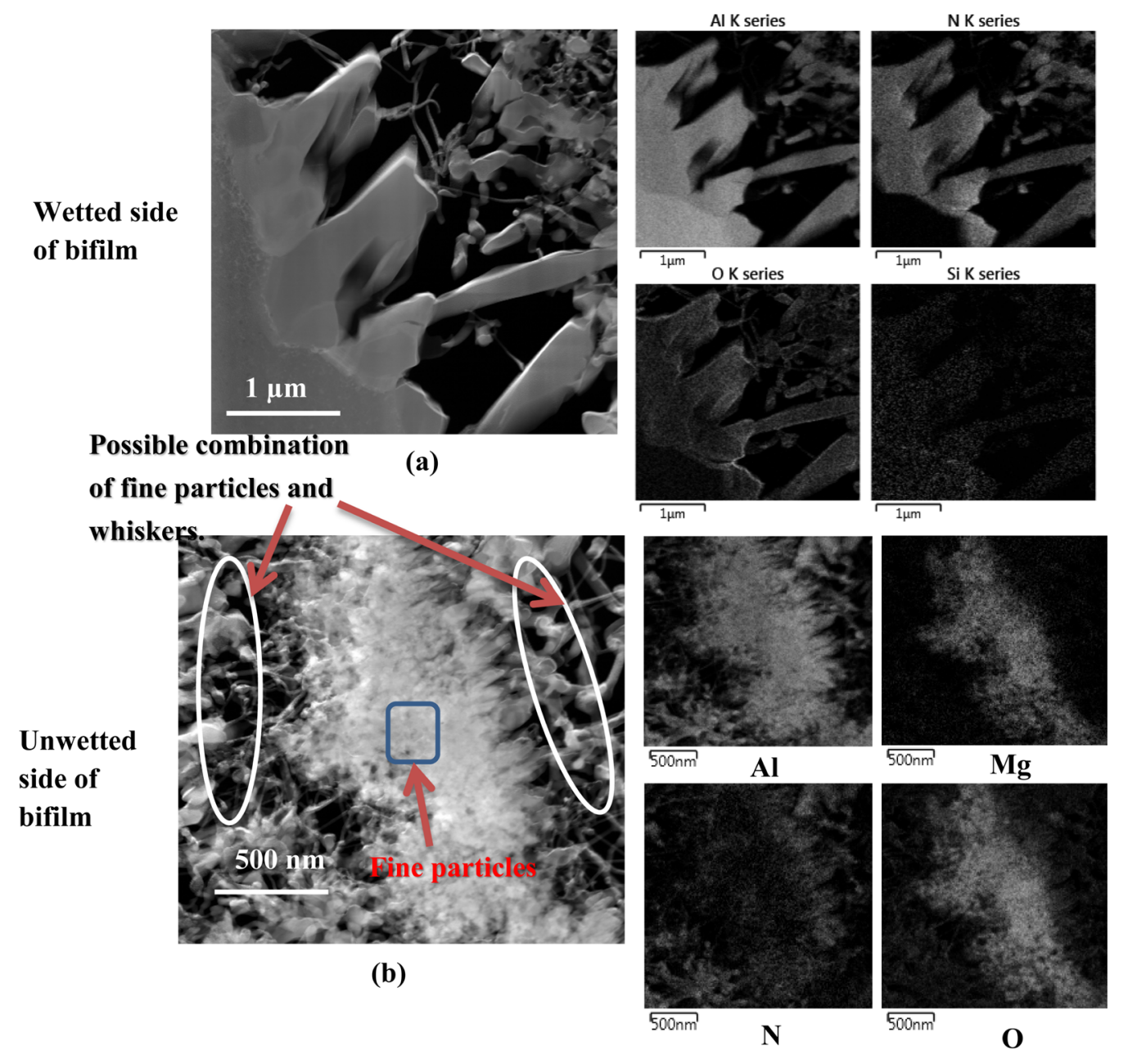

Fig. 13-EDX mapping of high magnification image of the area in (a) X1 (wetted side) and (b) X2 (unwetted side) from Fig. 11 respectively.

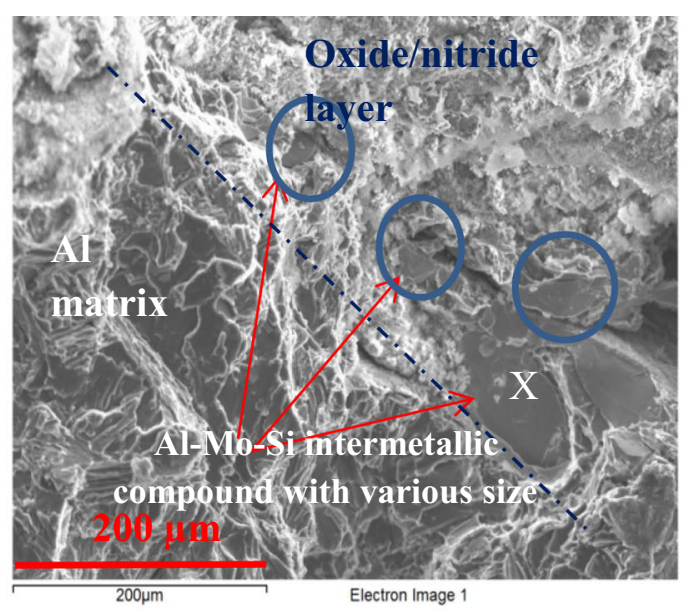

(a)

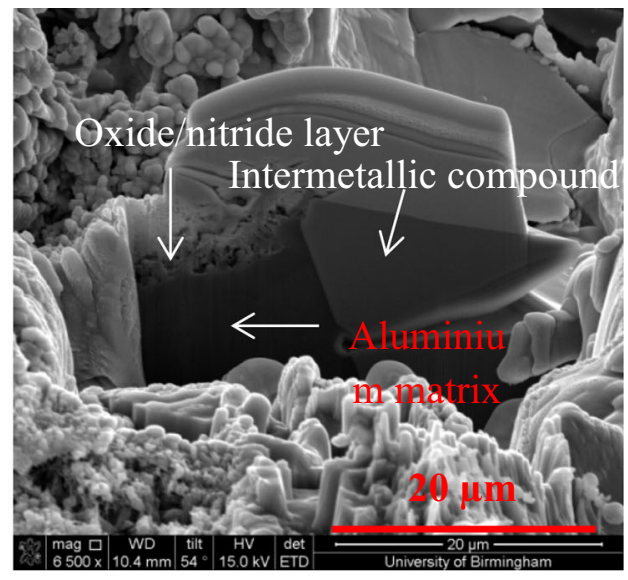

(b)

Fig. 14 - (a) Al-Mo-Si intermetallic compounds with different sizes on the side of double oxide film defect; $(b)$ Cross-section view of the intermetallic compound. 
dissolved $\mathrm{H}$ into and perhaps through the intermetallic phase(s), affecting the flux of $\mathrm{H}$ through the intermetallic phase.

In this work, the improved Weibull Moduli of the 2L99 + Mo castings, compared with 2L99 alloy castings as well as the reduced bubble size in bubble trapping experiment in 2L99 + Mo alloy, suggested that any effect of the inflation of the bifilm by $\mathrm{H}$ may have been outweighed by the consumption of the entrapped atmosphere resulting in a reduction in bifilm size and the associated increase in mechanical properties found.

\section{CONCLUSIONS}

1. A bubble trapping experiment suggested that the addition of Mo produced a significant increase in the consumption rate of a trapped bubble in 2L99 alloy, by 60 pet.

Table VI. Composition of the Intermetallic Compound

\begin{tabular}{lcccc}
\hline Elements & Mo & Si & Al & O \\
\hline Concentration (at. \%) & 32.9 & 65.3 & 0.1 & 0.1 \\
\hline
\end{tabular}

2. Tensile test result suggested that the addition of 0.4 wt pct Mo have significantly improve the Weibull moduli of UTS and Pct Elongation. In addition, the mean value for UTS and Pct Elongation were improved by 22 pct and 108 pct, respectively.

3. Examination of the bifilm from 2L99 alloy castings suggested that the oxide film defect were tangled with the oxide thickness up to hundreds nm. High magnification image showed that the oxide layer consists of oxide particles for 10 to $80 \mathrm{~nm}$.

4. A Mo addition was found to significantly alter the morphology and structure of the bifilm defect. A duplex layer was discovered on the surface of the bifilm defects, which consisted of nitride particles at the wetted side and spinel particles on the unwetted side. The thickness of the surface layer of AlN for Mo modified 2L99 castings ranged from 4 to $33 \mu \mathrm{m}$.

5. Intermetallic compounds were seen associated with bi-film defects. These phases might nucleated on the bifilm defect and might play a role in creating the rupture of the orignal spinel layer, which encourage the consumption of the entrapped atmosphere, reduce the defect size and lead to an improvement in the mechanical properties.

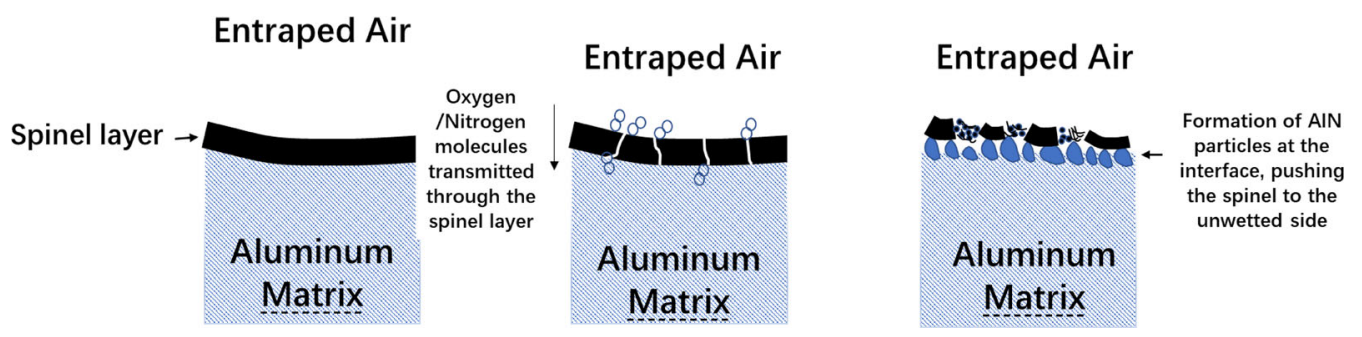

Fig. 15-Explanation to the formation of nitride containing particle layer.

Table VII. Lattice Mismatch Calculation for $\mathrm{MgAl}_{2} \mathrm{O}_{4}$ and $\mathrm{Mo}(\mathrm{Si}, \mathrm{Al})_{2}$

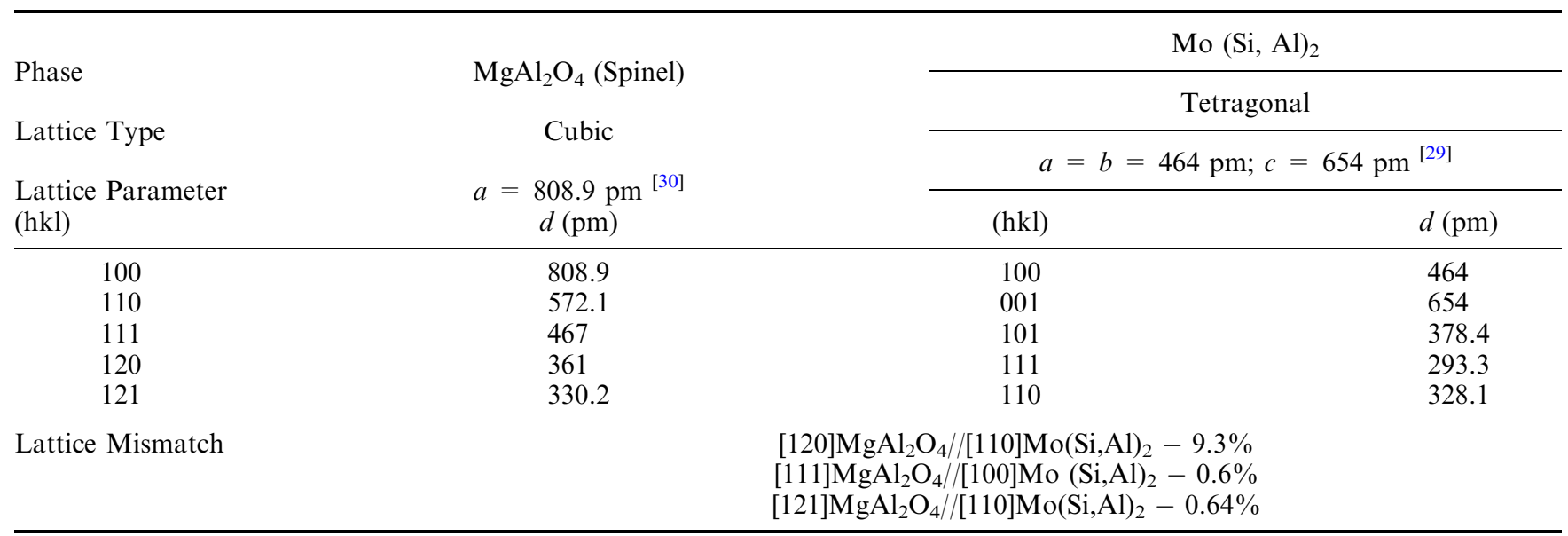




\section{ACKNOWLEDGEMENTS}

The author would like to acknowledge the School of Metallurgy and Materials, University of Birmingham for supporting this research work. Mr. A. J. Caden and Dr. KeeHyun Kim from School of Metallurgy and Materials, University of Birmingham were also greatly acknowledged.

\section{CONFLICT OF INTEREST}

The authors declare that they have no conflict of interest.

\section{OPEN ACCESS}

This article is licensed under a Creative Commons Attribution 4.0 International License, which permits use, sharing, adaptation, distribution and reproduction in any medium or format, as long as you give appropriate credit to the original author(s) and the source, provide a link to the Creative Commons licence, and indicate if changes were made. The images or other third party material in this article are included in the article's Creative Commons licence, unless indicated otherwise in a credit line to the material. If material is not included in the article's Creative Commons licence and your intended use is not permitted by statutory regulation or exceeds the permitted use, you will need to obtain permission directly from the copyright holder. To view a copy of this licence, visit http://creativec ommons.org/licenses/by/4.0/.

\section{REFERENCE}

1. J. Campbell: Castings, 2nd ed., Butterworth-Heinemann, Oxford, 2001, pp. 17-67.

2. J. Runyoro, S.M.A. Boutorati, and J. Campbell: AFS Trans., 1992, vol. 37, pp. 225-34.

3. N.-W. Lai, PhD Thesis, 2004, University of Birmingham: Birmingham.

4. X. Dai, X. Yang, J. Campbell, and J. Wood: Mater. Sci. Eng. A, 2003, vol. 354, pp. 315-25.
5. M. Cox, M. Wickins, J.P. Kuang, R.A. Harding, and J. Campbell: Mater. Sci. Tech., 2000, vol. 16, pp. 1445-52.

6. L.S.S. Aubrey, J.R. Schmahl, and M.A. Cummings: AFS Trans., 1993, vol. 101, pp. 59-69.

7. B.C. Sirrell and J. Campbell: AFS Trans., 1990, vol. 105, pp. 64554.

8. C. Nyahumwa, N.R. Green, and J. Campbell: AFS Trans., 1998, vol. 106, pp. 215-23.

9. W.C. Sleppy and J. Electrochem: Soc., 1961, vol. 108, pp. 10971102.

10. R. Fuoco and E.R. Correa: AFS Trans., 1999, vols. 99-85, pp. $287-94$.

11. S. Impey, D. Stephenson and J. Nicholls: in Proc. 2nd Int. Conf. on the Microscopy of Oxidation, 1993, Selwyn College, The University of Cambridge, Cambridge, pp. 323-27.

12. R. Raiszadeh and W.D. Griffiths: Metall. Mater. Trans. B, 2006, vol. 37, pp. 865-71.

13. M.A. El-Sayed, H.G. Salem, A.Y. Kandeil and W.D.Griffiths: Metall. and Mater. Tran. B, 2014, vol. 45(4), pp. 1398-1406.

14. M. Aryafar, R. Raiszadeh, and A. Shalbafzadeh: J. Mater. Sci., 2010, vol. 45, pp. 3041-51.

15. A.J. Gerrard and W.D. Griffiths: Shape Casting: 5th International Symposium, TMS, Springer, Cham, 2014, pp. 269-76.

16. N.R. Green and J. Campbell: Mater. Sci. Eng. A, 1993, vol. 173, pp. 261-66.

17. W.D. Griffiths, A.J. Caden, and Q. Chen: Mater. Sci. Tech., 2017, vol. 33, pp. 2212-22.

18. Q. Chen, A.J. Caden, and W.D. Griffiths: Advances in the Science and Engineering of Casting Solidification, TMS, Wiley, New York, 2015, pp. 121-28.

19. S. Impey, D.J. Stephen, and J.R. Nicholls: in Int. Conf. on Microscopy of Oxidation, 1990, University of Cambridge, pp. 238-44.

20. L. Lu and A.K. Dahle: Metall. Mat. Trans A, 2005, vol. 36, pp. 819-35.

21. M. Tiryakioğlu, D. Hudak, and G. Ökten: Mater. Sci. Eng. A, 2009, vol. 527, pp. 397-99.

22. D. Hudak and M. Tiryakioğlu: Mater. Sci. Eng. A, 2011, vol. 528, pp. 8028-30.

23. D.L. Belitskus: Oxid. Met., 1974, vol. 8, pp. 303-307.

24. I. Haginoya and T. Fukusako: TransJapan Inst. Met., 1983, vol. 24, pp. 613-19.

25. M.P. Silva and D.E.J. Talbot: in Light Metals, TMS, 1989, pp.137.

26. C.N. Cochran, D.L. Belitskus, and D.L. Kinosz: Metal. Trans. B., 1977, vol. 8, pp. 323-32.

27. C. Guo, C. Li, P.J. Masset, and Z. Du: Calphad, 2012, vol. 36, pp. $100-109$.

28. B.L. Bramfitt: Metall. Trans., 1970, vol. 1, pp. 1987-95.

29. T. Tabaru, K. Shobu, M. Sakamoto, and S. Hanada: Intermetallics, 2006, vol. 12, pp. 33-41.

30. K.E. Sickafus and J.M. Wills: J. Am. Ceram. Soc., 1999, vol. 82, pp. 3279-92.

Publisher's Note Springer Nature remains neutral with regard to jurisdictional claims in published maps and institutional affiliations. 